\title{
A RELAÇÃO ENTRE OS VALORES DE TEMPERATURA SUPERFICIAL TERRESTRE (TST), O USO E COBERTURA DO SOLO E A TOPOGRAFIA NO MUNICÍPIO DE MINAÇU-GO (2001)
}

\author{
THE RELATION BETWEEN THE VALUES OF LAND SURFACE \\ TEMPERATURE (LST), LAND USE AND COVER AND THE \\ TOPOGRAPHY IN THE CITY OF MINAÇU-GO (2001)
}

\author{
LA RELATION ENTRE LES VALEURS DE LA TEMPÉRATURE DE \\ SURFACE TERRESTRE (TST), L'UTILISATION ET OCCUPATION DU \\ SOL ET DE LA TOPOGRAPHIE DE LA VILLE DE MINAÇU-GO (2001)
}

Diego Tarley Ferreira Nascimento

Técnico em Meio Ambiente pelo Centro Federal de Educação Tecnólogica CEFET-GO Graduado em Geografia e mestrando do Programa de Pesquisa e Pós-Graduação em Geografia do Instituto de Estudos Socioambientais - IESA/UFG. Goiânia/GO.

Câmpus Samambaia (Câmpus II) - Goiânia-GO, CEP:74001-970

E-mail: diego.tarley@gmail.com.

Silvio Braz de Sousa

Técnico em Mineração pelo Centro Federal de Educação Tecnólogica CEFET-GO e graduando em Geografia do Instituto de Estudos Socioambientais - IESA/UFG. Goiânia/GO.

E-mail: sbsousa@geografia.grad.ufg.br

Ivanilton José de Oliveira

Doutor em Geografia Humana pelo Departamento de Geografia da Universidade de São Paulo - FFLCH/USP.

Prof. Dr. do Instituto de Estudos Socioambientais - IESA/UFG. Goiânia/GO.

E-mail: ivanilton.oliveira@gmail.com. 


\title{
Resumo
}

Alterações ambientais promovidas pelas mudanças no uso das terras, como a variação da condição da Temperatura Superficial Terrestre (TST), são relevantes, considerandose sua influência no sistema hidrológico, terrestre e atmosférico. O presente estudo utiliza o sensoriamento remoto para avaliar a influência do uso e cobertura do solo na variação espacial da temperatura superficial terrestre, principalmente em consonância com outro elemento fundamental na caracterização do campo térmico, a topografia. Para execução do presente trabalho, procedeu-se a elaboração de mapas de Uso $e$ Cobertura do solo, Hipsométrico e de Temperatura Superficial Terrestre, visando estabelecer o cotejamento entre eles e mensurar a correlação entre suas classes. Os produtos cartográficos demonstram que há uma correlação direta e inversa entre certas coberturas naturais e a TST. A hipsometria, em geral, também apresentou correlação direta e inversa com as temperaturas superficiais, com as maiores cotas altimétricas registrando os menores valores de temperatura e os maiores valores associados às depressões topográficas.

Palavras-chaves: temperatura superficial terrestre (TST), uso da terra, hipsometria, Minaçu (GO), sensoriamento remoto

\begin{abstract}
Environmental changes promoted by alterations in land use such as changes in the condition of Land Surface Temperature (TST), are relevant, considering its influence on the hydrological system, terrestrial and atmospheric. This study uses remote sensing to assess the influence of land cover and spatial variation in land surface temperature, especially in line with another key element in the characterization of the thermal field: the topography. To implement this work, we proceeded to produce maps of Use and Land cover, Hypsometric and Land Surface Temperature, in order to establish mutual comparison between them and measure the correlation between their classes. The cartographic products show that there is a correlation between forward and reverse some natural hedges and TST. The topographic generally also correlated directly and inversely with the surface temperatures, with the highest altitudes recording the lowest temperature and the highest values associated with topographic depressions.
\end{abstract}

Key-words: Land surface temperature (LST), land use, hipsometry, Minaçu (GO), remote sensing

\section{Résumé}

Les changements environnementaux promu par des changements dans l'utilisation des sols tels que les changements dans la condition de la température de la surface terrestre (TST), sont pertinentes, compte tenu de son influence sur le système hydrologique, le sol et l'air. Cette étude utilise la télédétection pour évaluer l'influence de la couverture terrestre et la variation spatiale de la température de la surface terrestre, surtout en ligne avec un autre élément clé dans la caractérisation du champ thermique, la topographie. Pour mettre en œuvre ce travail, nous avons procédé pour produire des cartes d'utilisation et de la couverture terrestre, hypsométrique et température de surface de la terre, afin d'établir la comparaison réciproque entre eux et mesurer la corrélation entre leurs classes. Les produits cartographiques montrent qu'il existe une corrélation entre le 
terme et de renverser certaines couvertures naturelles et TST. Les accidents topographiques également corrélée directement et inversement proportionnelle à la température de surface, avec des contingents plus importants d'enregistrement altimétrique la plus basse température et les valeurs les plus élevées associées à des dépressions topographiques.

Mots-clés: température de surface terrestre (TST), utilisation des terres, hypsométrie Minaçu (GO), télédétection

\section{Introdução}

Mudanças no uso e na cobertura da terra estão entre os principais ocasionadores de uma gama de impactos de ordem ambiental, social e/ou econômica. Em particular, são relevantes as alterações ambientais relacionadas à condição da temperatura superficial terrestre, devido sua influencia no ciclo de umidade e calor na superfície e atmosfera, configurando o sistema hidrológico, terrestre e atmosférico. Interferindo assim, nas características do solo, da vegetação e da própria paisagem de determinado local.

Segundo Gusso et al. (2007, p. 231), a temperatura da superfície terrestre (TST) "é determinada a partir da detecção da radiação de ondas longas emitida na faixa do infravermelho e detectada por sensores orbitais", sendo um parâmetro físico que diz respeito ao fluxo de calor dado em função do balanço de radiação que chega e que sai de um corpo (AYOADE, 2001), tendo uma variação espacial - influenciada pela quantia de insolação recebida, a natureza da superfície, a distância a partir dos corpos hídricos, o relevo, a natureza dos ventos predominantes - e temporal - condicionada principalmente pelas variações sazonais no volume de radiação recebida, que varia conforme a latitude e com o grau de continentalidade.

É esperado que diferentes usos e coberturas do solo apresentem distintos valores de temperatura de determinada superfície, considerando a diferença de absorção, emissividade e irradiação existente entre eles. Todavia, a produção em geografia física carece de estudos que avaliem de forma mais sistemática a correlação existente entre as formas de uso e cobertura da terra e variações no campo térmico superficial, principalmente em consonância com outros elementos que venham a influenciar tais parâmetros, como a topografia. 
O presente estudo almeja justamente averiguar as possibilidades do uso do sensoriamento remoto para sanar, em termos, essa lacuna, principalmente ao ponderar a capacidade dos sensores dos satélites em detectar a radiação em ondas longas emitida na faixa do infravermelho termal (compreendida entre o intervalo de $8-14 \mu \mathrm{m}$ do espectro eletromagnético) que varia em função de sua temperatura (STEINKE; STEINKE; SAITO, 2004). O ensaio buscou ressaltar a possibilidade de levantar a temperatura de determinado local ou objeto por meio da transformação dos tons de cinza das imagens termais em valores de temperatura aparente da superfície, baseando-se para isso na aplicação de um algoritmo.

Considerando-se a inexistência de uma rede de estações meteorológicas que possam fornecer dados de áreas relativamente extensas, mas pouco povoadas, como é o caso da maior parte do território brasileiro, o sensoriamento remoto surge como uma eficiente técnica de investigação, por subsidiar a aquisição de uma gama de dados de qualquer localidade do globo terrestre, com registros temporais constantes. Não obstante, ressaltando-se ainda a grande dificuldade de ter acesso aos dados de temperatura do ar, informações referentes aos valores de temperatura da superfície terrestre se destacam em pesquisas que dizem respeito ao fluxo de radiação de dada localidade.

Com base nessas premissas, objetiva-se analisar a influência do uso e cobertura do solo e da topografia no comportamento espacial simultâneo da temperatura superficial terrestre utilizando-se do sensoriamento remoto, tendo como área de estudo o município de Minaçu, em Goiás.

Minaçu está localizada no extremo norte do estado de Goiás, a 504 km da capital do estado (Figura 01). O nome do município é oriundo do idioma tupi-guarani, significando "mina grande". Isto porque a cidade se constituiu graças à implantação do parque industrial da SAMA Minerações Associadas (anteriormente, Sociedade Anônima Mineração de Amianto), na região da Serra de Cana Brava, para exploração do minério de amianto. Esse fato levou alguns proprietários de terras a doarem parte de suas glebas para implantação de um povoado que, através da Lei Estadual nº 8.085, de 1976, se desvinculou administrativamente de Uruaçu, elevando-se à categoria de cidade e sede municipal. 

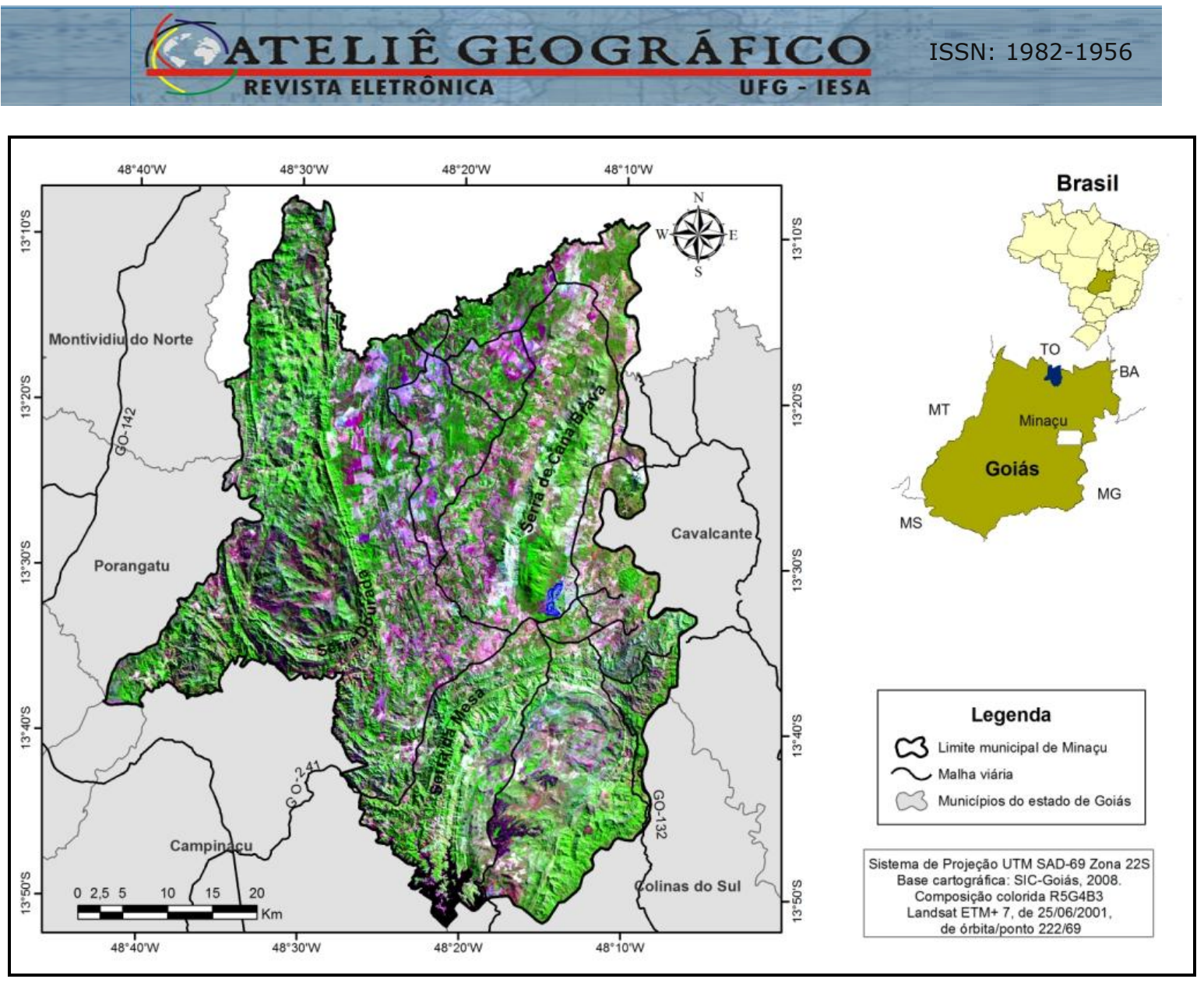

Figura 01: Mapa de localização de Minaçu-GO (baseado em imagem Landsat de 2001).

Com uma população estimada pelo IBGE (2007) em 31.041 habitantes e uma área territorial de $2.861 \mathrm{~km}^{2}$, o município se destaca nas atividades de pecuária e mineração. Em termos fisiográficos, Minaçu apresenta a ocorrência de grandes feições morfoestruturais, como a Serra da Mesa, ao sul, a Serra de Cana Brava, a nordeste, e a Serra Dourada, a oeste e noroeste - que são, em grande parte, fruto de estruturas geológicas antigas, submetidas a dobramentos e falhamentos. Associado a esse relevo irregular, o município também registra a presença de expressivos trechos com remanescentes da vegetação de cerrado.

Nas últimas décadas, as características hidrográficas da região também propiciaram a sua escolha para a implantação de dois grandes reservatórios para usinas hidrelétricas, Serra da Mesa e Cana Brava, cujos lagos inundaram significativas porções de terra do município.

\section{Metodologia}


Para execução do presente trabalho, procedeu-se a elaboração de mapas de Uso $e$ Cobertura do solo, Hipsométrico e de Temperatura Superficial Terrestre, visando estabelecer o cotejamento entre eles e mensurar a correlação entre suas classes.

Para tanto, foram coletadas, no site do Instituto Nacional de Pesquisas Espaciais (INPE), imagens do sensor ETM+ do satélite Landsat 7, de 2001, de órbita/ponto 222/69, sendo as bandas 3, 4, 5 e 6 (bandas do azul, verde, vermelho e infravermelho termal, respectivamente). Ressalta-se que a escolha do sensor ETM+ se deve à sua boa resolução espacial, tanto nas bandas utilizadas na análise do uso do solo (15m) quanto na banda termal (60m). A escolha do período para análise, por sua vez, considerou a pequena disponibilidade temporal de imagens do sensor do satélite Landsat 7 , que foi lançado em 1999 e desativado já em 2003.

Os dados topográficos foram obtidos a partir de imagens da Shuttle Radar Topographic Mission (SRTM), adquiridos no site da Embrapa Monitoramento por Satélites (http://www.relevobr.cnpm.embrapa.br). Os demais dados cartográficos (drenagem, limites municipais, área urbana etc.) foram adquiridos em formato shapefile, na base de dados do site do Sistema Estadual de Estatística e de Informações Geográficas de Goiás (SIEG).

A data das imagens coletadas (fundamentalmente da banda termal) refere-se ao mês de junho, justamente por neste período do ano ainda se ter um considerável ganho de radiação solar e certa estabilidade atmosférica - elementos importantes para levantamento do campo térmico superficial. Convém ressaltar que o período em questão (primavera) associa-se aos maiores valores de temperatura do ar (NASCIMENTO; LUIZ, 2007).

Foram utilizados os softwares ArcGIS 9.2, para pré-processamento das imagens (registro e máscara), elaboração do mapa hipsométrico, cálculos de área e finalização dos produtos cartográficos; IDRISI versão Andes, para elaboração do mapa de temperatura superficial terrestre, por meio de seu módulo thermal, que transforma os valores de reflectância registrados pela banda termal do sensor orbital em valores de temperatura, já em graus Celsius; e o ENVI 4.5, para elaboração do mapa de uso e cobertura do solo (com definição das classes área urbana, mineração, pastagens e corpos hídricos), a partir de uma classificação supervisionada, com emprego do algoritmo de máxima verossimilhança. 
De posse dos produtos cartográficos, realizou-se quantificação, em termos de área ocupada em $\mathrm{km}^{2}$, de cada classe do mapa de uso e cobertura do solo e do mapa de temperatura superficial. Valendo-se das ferramentas do ArcGIS, foram realizadas as tabulações cruzadas entre os mapas (temperatura superficial versus uso e cobertura do solo; temperatura superficial versus hipsometria).

\section{Resultados e Discussão}

\section{A relação entre temperatura superficial terrestre (TST) e uso e cobertura do solo}

O mapa de Temperatura superficial (Figura 2) do município de Minaçu, referente ao mês de junho de 2001 - início do inverno (seco) verificado na região central do país -, mostra um claro predomínio do intervalo de temperaturas compreendidas entre $22^{\circ} \mathrm{C}$ e $26^{\circ} \mathrm{C}$.

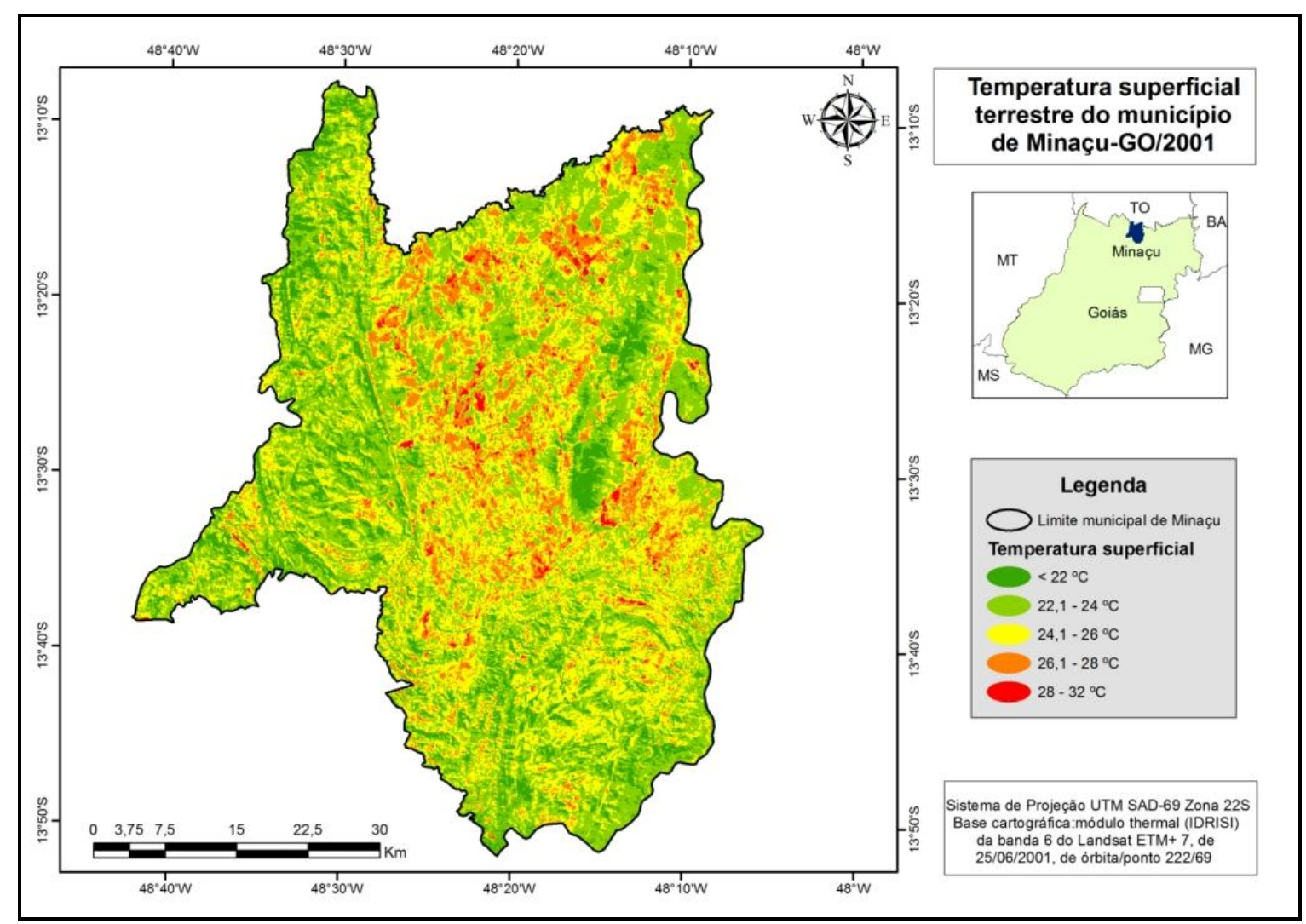

Figura 02: Mapa das temperaturas superficiais - Município de Minaçu (GO), junho/2001. 
As temperaturas abaixo de $22^{\circ} \mathrm{C}$ são registradas apenas em algumas faixas, grosso modo, de sentido norte-sul, sobre áreas de relevos altimetricamente superiores, a leste e a oeste, no município. Já os intervalos de temperaturas mais elevadas (entre $26,1^{\circ}$ e $32^{\circ} \mathrm{C}$ ) aparecem de formas descontínuas, em sua maioria, nas áreas ao centro e norte do munícipio, num mosaico de polígonos formando um conjunto, e, no leste do município, numa extensa faixa quase totalmente isolada por barreiras orográficas.

A quantificação das áreas ocupadas por cada classe de temperatura (Tabela 01) corrobora a leitura visual do mapa. Enquanto a classe de temperaturas entre $22^{\circ}$ e $26^{\circ} \mathrm{C}$ recobre $75,5 \%$ da área total do município, as temperaturas mais elevadas, entre $26,1^{\circ} \mathrm{e}$ $32^{\circ} \mathrm{C}$, perfazem $13,2 \%$. Já as menores temperaturas, abaixo de $22^{\circ} \mathrm{C}$ representam apenas $12,6 \%$ da área total.

\section{Tabela 01 - Área e porcentagem das classes de temperatura superficial terrestre.}

\begin{tabular}{|c|r|r|}
\hline Classes de temperatura & Área $\left(\mathrm{km}^{2}\right)$ & $\%$ \\
\hline 20,1 a $22^{\circ} \mathrm{C}$ & 323,71 & 12,6 \\
\hline 22,1 a $24^{\circ} \mathrm{C}$ & $1.146,62$ & 40,0 \\
\hline 24,1 a $26^{\circ} \mathrm{C}$ & $1.015,68$ & 35,5 \\
\hline 26,1 a $28^{\circ} \mathrm{C}$ & 340,56 & 11,9 \\
\hline 28,1 a $32^{\circ} \mathrm{C}$ & 37,06 & 1,3 \\
\hline Total* $^{*}$ & $\mathbf{2 . 8 6 4 , 0 0}$ & $\mathbf{1 0 0 , 0}$ \\
\hline
\end{tabular}

*Valor total mensurado pelo SIG confere com o valor mensurado pelo IBGE (unidade territorial municipal).

Também foram quantificados os percentuais ocupados por cada classe de uso e cobertura do solo no município de Minaçu (Tabela 02). Com base nesses dados, é importante registrar que, embora seja muito expressiva em termos econômicos, a mineração é incipiente em área de ocorrência, perfazendo cerca de 0,2\% do território municipal. A jazida de exploração do amianto, da empresa SAMA, encontra-se a oeste da área urbana e ocupa uma extensão maior do que a própria cidade - que, aliás, nasceu e cresceu em decorrência da atividade mineradora. 
Tabela 02: Área e porcentagem das classes de uso e cobertura do solo.

\begin{tabular}{|l|r|r|}
\hline \multirow{2}{*}{$\begin{array}{c}\text { Classes de uso e cobertura do } \\
\text { solo }\end{array}$} & \multicolumn{2}{|c|}{ Área } \\
\cline { 2 - 3 } Área urbana & $\mathrm{km}^{2}$ & $\%$ \\
\hline Mineração & 6,50 & 0,23 \\
\hline Pastagem & 5,28 & 0,18 \\
\hline Vegetação & $1.311,01$ & 45,78 \\
\hline Drenagens & $1.503,55$ & 52,50 \\
\hline Total & 38,41 & 1,34 \\
\hline
\end{tabular}

* O valor total mensurado pelo SIG, em $\mathrm{km}^{2}$, confere com os dados do IBGE (unidade territorial municipal).

O mapa de Uso e Cobertura do solo (Figura 03), por sua vez, permite visualizar a existência de extensos trechos ainda recobertos com vegetação nativa de cerrado, embora as pastagens componham a classe mais significativa, em termos de área de ocorrência. As áreas contínuas de cerrado são mais expressivas no oeste e no noroeste do município, embora também ocorram de forma fragmentada em meio às pastagens que dominam no restante do território municipal. Em função do ano analisado, 2001, a massa d'água mais expressiva é apenas o trecho norte do Lago de Serra da Mesa (no extremo sul do município), oriundo do represamento do rio Maranhão para abastecer a Usina Hidrelétrica de Serra da Mesa.

A inexistência de áreas mapeadas como agricultura, seja na forma de lavouras temporárias, seja como lavouras permanentes, deve-se, primordialmente, à escala de mapeamento - ancorada na resolução do sensor utilizado -, que inviabiliza identificar polígonos muito reduzidos, representando as pequenas faixas de terras com cultivos dessa natureza, existentes nas propriedades rurais do município. Ressalte-se que isso é, também, um registro das restrições impostas pelo meio físico, que conjuga terrenos de relevo irregular a solos quimicamente pobres para o cultivo de lavouras comerciais, como as predominantes em outras regiões do território goiano. 

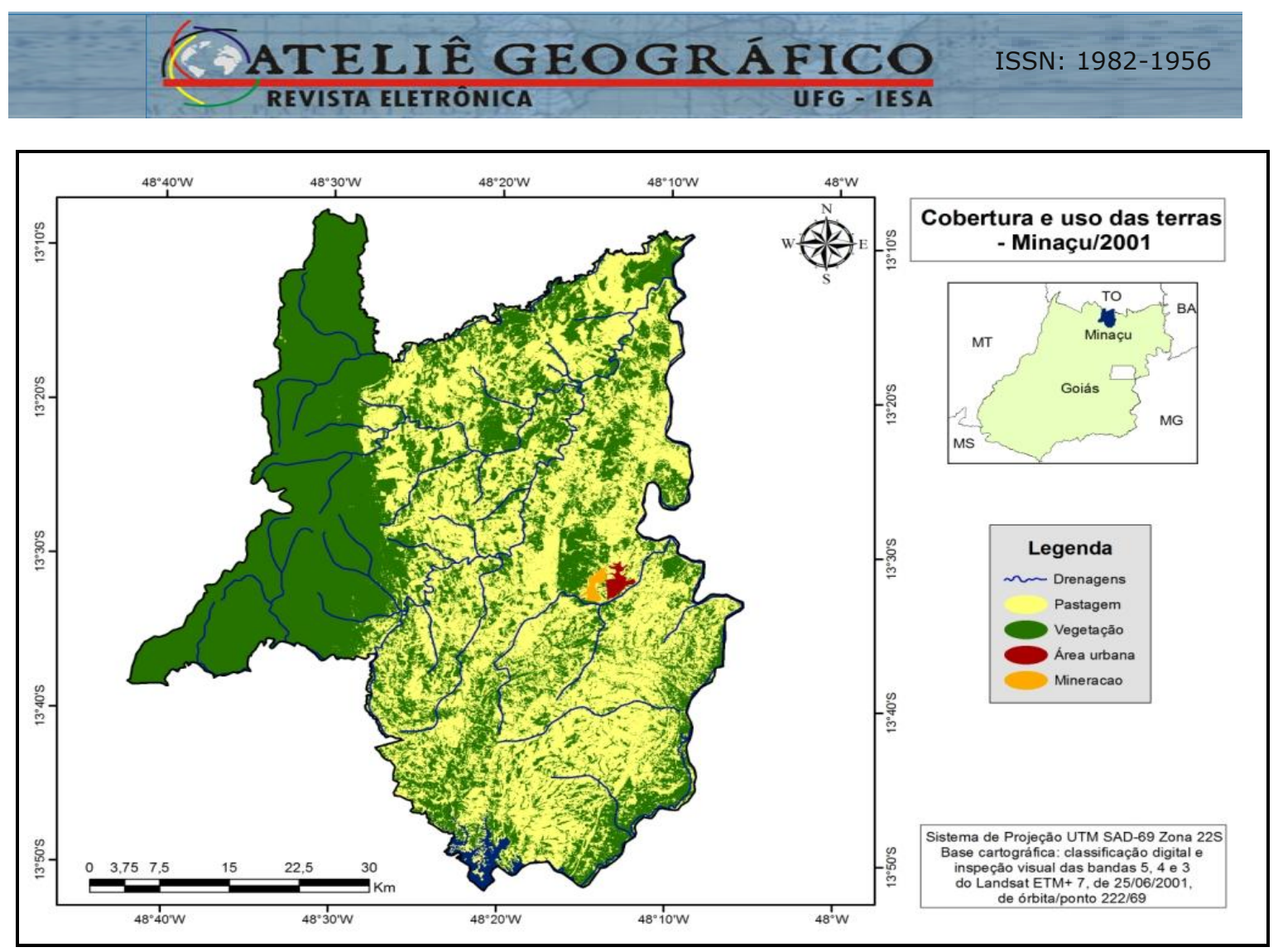

Figura 03: Mapa do uso e cobertura do solo no município de Minaçu (GO), no ano de 2001.

Quando comparados os mapas de uso e cobertura do solo e temperaturas superficiais, a distribuição geográfica das faixas de temperaturas mais amenas guarda estreita relação com a presença de áreas contínuas de vegetação, em especial no oeste do município. A tabulação cruzada realizada entre os temas (Tabela 03) permite vislumbrar melhor as correlações existentes.

Tabela 03: Tabulação cruzada demonstrando o percentual de uso e cobertura do solo contida em cada faixa de temperatura. Resultados em porcentagem.

\begin{tabular}{|c|c|c|c|c|c|c|}
\hline \multirow[b]{2}{*}{ Uso e cobertura do solo } & \multicolumn{5}{|c|}{ Temperatura (graus centígrados) } & \multirow[b]{2}{*}{ Total } \\
\hline & $<22$ & $\begin{array}{c}22,1 \mathrm{a} \\
24\end{array}$ & $\begin{array}{c}24,1 \mathrm{a} \\
26\end{array}$ & $\begin{array}{c}26,1 \mathrm{a} \\
28\end{array}$ & $\begin{array}{c}28,1 \text { a } \\
32\end{array}$ & \\
\hline Área urbana & 0,0 & 1,4 & 32,3 & 63,2 & 3,1 & 100,0 \\
\hline Mineração & 0,0 & 3,8 & 25,4 & 39,8 & 31,1 & 100,0 \\
\hline Pastagem & 3,0 & 28,9 & 45,2 & 20,5 & 2,4 & 100,0 \\
\hline Vegetação & 18,2 & 49,9 & 27,5 & 4,1 & 0,3 & 100,0 \\
\hline Drenagens & 25,8 & 49,2 & 16,6 & 7,2 & 1,2 & 100,0 \\
\hline
\end{tabular}


Grosso modo, enquanto as classes área urbana e mineração apresentam parte majoritária de suas áreas $(98,6 \%$ e 96,3\%, respectivamente) associadas a temperaturas mais elevadas (acima de $24^{\circ} \mathrm{C}$ ), as classes vegetação e drenagem apresentam-se associadas a temperaturas mais amenas, abaixo de $24^{\circ} \mathrm{C}(68,1 \%$ e $75 \%$ de suas áreas, respectivamente). A classe pastagem, contudo, apresenta uma alta variabilidade no tocante às temperaturas encontradas, com ligeiro predomínio da classe entre $24,1^{\circ}$ e $26^{\circ}$ C.

\section{A relação entre temperatura superficial terrestre (TST) e hipsometria}

O mapa hipsométrico do município de Minaçu (Figura 04) demonstra a presença de três compartimentos mais elevados, correspondentes às serras Dourada, a oeste, Cana Brava, a leste, e da Mesa, a sudeste.

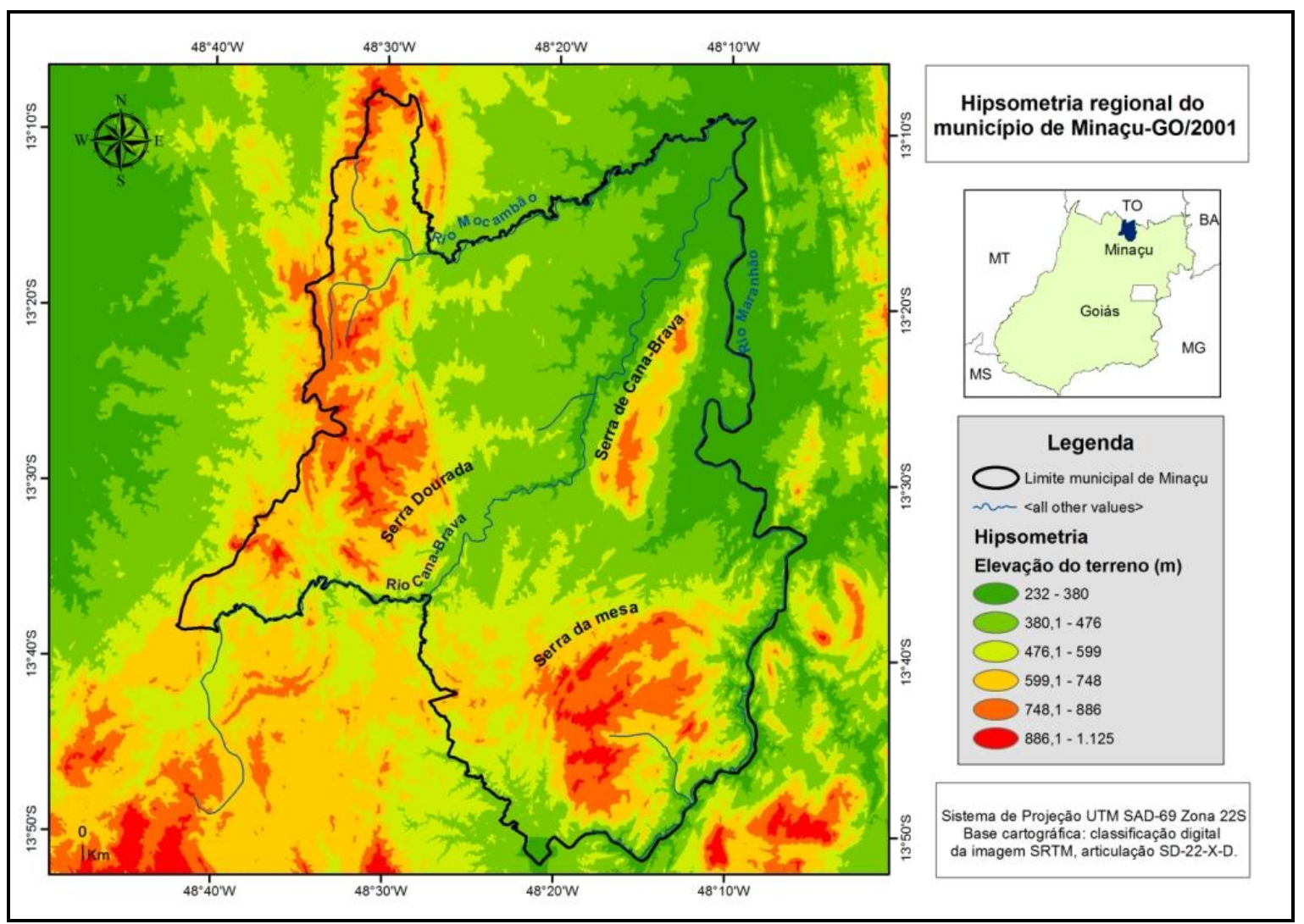

Figura 04: Mapa Hipsométrico do município de Minaçu (GO). 
O município é drenado pela rede hidrográfica do rio Maranhão, um dos principais formadores do rio Tocantins, com sentido predominante, grosso modo, de sul para norte. O rio Cana Brava corta o município de sudoeste para nordeste, enquanto o rio Mocambão o faz no limite norte, ambos confluindo no rio Maranhão no limite nordeste do município. A drenagem está associada às áreas deprimidas da topografia local, cujas altitudes decaem de sudoeste para nordeste.

Quando observadas as classes hipsométricas em tabulação cruzada com as classes de temperatura (Tabela 04), permite-se vislumbrar melhor as correlações existentes. A priori, parte-se da premissa de que as maiores temperaturas estariam nos menores níveis altimétricos, enquanto as menores temperaturas estariam justamente nas maiores altitudes.

Tabela 04: Tabulação cruzada demonstrando o percentual de hipsometria contida em cada classe de temperatura. Resultados em porcentagem.

\begin{tabular}{|c|c|c|c|c|c|c|}
\hline & \multicolumn{5}{|c|}{ Temperatura (graus Celsius) } & \multirow{2}{*}{ Total } \\
\cline { 2 - 6 } Hipsometria (m) & $<22$ & 22,1 a 24 & 26 & 28 & 32 & $(\%)$ \\
\hline 232 a 380 & 8,25 & 35,71 & 35,38 & 17,61 & 3,05 & $\mathbf{1 0 0}$ \\
\hline 380,1 a 476 & 6,66 & 31,79 & 37,52 & 20,28 & 3,76 & $\mathbf{1 0 0}$ \\
\hline 476,1 a 599 & 13,87 & 36,70 & 34,64 & 12,96 & 1,83 & $\mathbf{1 0 0}$ \\
\hline 599,1 a 748 & 20,71 & 40,18 & 30,63 & 7,77 & 0,71 & $\mathbf{1 0 0}$ \\
\hline 748,1 a 886 & 21,18 & 41,15 & 31,66 & 5,53 & 0,48 & $\mathbf{1 0 0}$ \\
\hline 886,1 a 1.125 & 16,28 & 42,17 & 37,30 & 4,03 & 0,22 & $\mathbf{1 0 0}$ \\
\hline
\end{tabular}

Contudo, pode-se observar, na tabela, que não necessariamente teremos a maior concentração de altas temperaturas na classe de menores altitudes (223 a $380 \mathrm{~m}$ ). No intervalo altimétrico seguinte (380,1 a 476m), há uma maior ocorrência de temperaturas mais elevadas, pois as temperaturas maiores que $24^{\circ} \mathrm{C}$ correspondem a $61,56 \%$ da área total dessa faixa altimétrica, em comparação aos 56,05\% no intervalo altimétrico inferior.

Tal fato pode ser justificado, provavelmente, pela presença dos cursos d'água, com destaque para os rios Mocambão, no limite norte do município, Maranhão, no 
limite leste, e Cana-Brava, que cruza o município em sentido sudoeste/nordeste. E também do lago Serra da Mesa, no extremo sul do município. Há, também, uma significativa proporção de cobertura vegetal nas cotas altimétricas mais inferiores. Esses elementos - drenagem e vegetação - somados, podem ter propiciado a redução dos valores de temperatura, atuando como aliviadores térmicos.

Nos intervalos altimétricos seguintes - e mais elevados -, nota-se uma redução gradativa e constante das áreas com maiores temperaturas (entre 26,1 e $32^{\circ} \mathrm{C}$ ), fato este que corrobora a premissa citada anteriormente. Contudo, isso cessa na comparação entre a classe de maiores altitudes (886,1 a $1.125 \mathrm{~m})$ e o intervalo anterior $(748,1 \mathrm{a} 886 \mathrm{~m})$. Verifica-se, nas maiores altitudes, um percentual menor de participação das temperaturas inferiores a $22^{\circ} \mathrm{C}$, quando comparada à classe altimétrica anterior. Possivelmente, isso decorre da classe altimétrica entre 886,1 e $1.125 \mathrm{~m}$ apresentar uma cobertura de solo revestida principalmente por pastagens, enquanto o intervalo altimétrico de 748,1 a 886m apresentar predomínio de cobertura vegetal nativa. A densidade da vegetação nativa, arbóreo-arbustíva (cerrados e matas), quando comparada às gramíneas (pastagens), pode justificar a redução dos valores das temperaturas superficiais.

\section{Considerações finais}

O sensoriamento remoto se firma como uma eficiente técnica de estudos de radiação superficial, considerando a representabilidade espacial dos dados, quando comparados a trabalhos que tratem de dados pontuais coletados em estações meteorológicas, bem como pela relativa facilidade de aquisição das informações.

Portanto, o sensoriamento remoto consegue sanar a grande lacuna de pesquisas que avaliem de forma mais sistemática a correlação existente entre as formas de uso e cobertura da terra e variações no campo térmico superficial, principalmente ao considerar a possibilidade da análise (e associação) de diferentes elementos, como a topografia, no presente trabalho.

Os dados obtidos neste ensaio permitem afirmar que, na área de estudo, é possível perceber uma correlação negativa entre a presença de cobertura vegetal e corpos hídricos e a variação da temperatura superficial terrestre. Ou seja, quanto maior a 
presença da vegetação e dos corpos d'água, menor tendem a ser as temperaturas superficiais.

Entretanto, a topografia tem maior influência na variação espacial das temperaturas superficiais, algo que é demonstrado claramente pelo decréscimo gradual das temperaturas quanto maiores forem as altitudes. Ainda que devamos destacar a importância do tipo de cobertura e sua influência na distorção dessa relação topografiatemperaturas - como visto no caso dos dois últimos intervalos altimétricos, com coberturas vegetais distintas.

Ou seja, o tipo de uso e cobertura do solo altera a influência significativa da topografia, mas a cobertura, sozinha, não apresenta uma correlação tão significativa com as temperaturas superficiais.

Finalmente, aponta-se a necessidade de novos trabalhos que abordem a influência do uso e cobertura do solo nos valores de temperatura superficial terrestre a partir da análise de séries históricas, haja vista a possibilidade de se verificar, por exemplo, o verdadeiro peso da ação antrópica na alteração do campo térmico superficial, independentemente da influência de outros elementos, como o topográfico, retratado no presente trabalho.

\section{Referências Bibliográficas}

AYOADE, J. O. Introdução a climatologia para os trópicos. 6. ed. Rio de Janeiro: Bertrand Brasil, 2001. 332 p.

GUSSO, A.; FONTANA, D. C.; GONÇALVES, G. A. Mapeamento da temperatura da superfície terrestre com uso do sensor AVHRR/NOAA. Pesquisa Agropecuária Brasileira. Brasília, v. 42, n. 2, p. 231-237, fev. 2007.

NASCIMENTO, D. T. F.; LUIZ, G. C. Levantamento do comportamento da mínima e máxima temperatura do ar em Goiânia-GO - 2000/2006. In: SIMPÓSIO BRASILEIRO DE GEOGRAFIA FÍSICA APLICADA. 12., Natal, jul. 2007. Anais do XII SBGFA. Natal, UFRN. 1 CD-ROM. 
STEINKE, E. T; STEINKE, V. A.; SAITO, C. H. Avaliação da estimativa da temperatura de superfície a partir de imagens de satélite Landsat TM 5 voltada para a gestão de bacias hidrográficas. In: SAITO, C. H. (org.). Desenvolvimento tecnológico e metodológico para mediação entre usuários e comitês de bacia hidrográfica. Brasília: Departamento de Ecologia da Universidade de Brasília, 2004. p. 41-64.

Recebido para publicação em abril de 2009 Aprovado para publicação em maio de 2009 